\title{
DOMINAÇÃO E MOBILIDADE EM MONIQUE SAINT-MARTIN
}

\author{
Marcus Roberto de Oliveira ${ }^{1}$
}

\begin{abstract}
Resumo: A abordagem dos processos de dominação e exercício do poder, junto aos rumos de mobilidade social, (escolar, profissional, geográfica, residencial, etc.) revela-se complexa, repleta de nuances que acabem exigindo instrumentais teóricos e metodológicos no intuito de uma construção disciplinada de conhecimentos sociológicos acerca de uma temática tão diversa. Diante de tal imperativo é possível identificar algumas significativas contribuições da obra de Monique de Saint-Martin. Assim, o presente texto tem como objetivo proporcionar uma sistematização de conceitos trabalhados pela socióloga francesa (em especial, os de fronteira, reconversão, ruptura e trajetória) que torne crível identificar uma atualização da ideia de classe social e as relevantes presenças das instituições familiares nos diversos campos sociais vigentes.
\end{abstract}

Palavras-chave: Monique de Saint-Martin. Fronteiras. Família. Capitais. Reconversão.

\section{DOMINATION AND MOBILITY IN MONIQUE SAINT-MARTIN}

\begin{abstract}
The approach to the processes of domination and the exercise of power, together with social mobility (school, professional, geographic, residential, etc.) is complex, full of nuances that end up requiring theoretical and methodological tools in order to A disciplined construction of sociological knowledge about such a diverse subject. Facing this imperative, it is possible to identify some significant contributions of the work of Monique de Saint-Martin. Thus, the present text aims to provide a systematization of concepts developed by the French sociologist (especially those of frontier, reconversion, rupture and trajectory) that makes it possible to identify an update of the idea of social class and the relevant presences of family institutions in the Various social fields.
\end{abstract}

Keywords: Monique de Saint-Martin. Borders. Family. Capitals. Reconversion.

- Enviado em 15/07/2017

- Aprovado em 28/07/2017

\footnotetext{
1 Doutorando em Sociologia pela Universidade Federal do Paraná (UFPR) e pesquisador do Núcleo de Estudos
} Paranaenses (NEP) da UFPR. Endereço eletrônico: $\underline{\text { mr_olivei@yahoo.com.br }}$ 


\section{Introdução}

As ações e performances de poder que estão interpostas nas numerosas estruturas das sociedades humanas abrangem as iniciativas de reprodução e legitimação de níveis de dominação, bem como os condicionantes históricos e sociais que permitem as ocorrências de tais processos. Nesse sentido, é importante destacar que esses fenômenos não são lineares e, portanto, seguem diversos reordenamentos ao longo da história. Desse modo, os êxitos e fracassos por parte dos agentes sociais envolvidos (indivíduo, instituição ou grupo) nestas empreitadas estão sistematicamente ligados às noções de acúmulos de capitais ${ }^{2}$, que permitem deslocamentos e conflitos, interiores e/ou exteriores, nos diversos campos sociais vigentes (BOURDIEU, 1996).

Nesta lógica, juntamente aos processos de dominação (o exercício do poder), os decursos de mobilidade social'; "escolar, profissional, geográfica, residencial", entre outras (LABACHE; SAINT-MARTIN, 2008, p. 334), também podem (e devem) ser abordados. No entanto, tal conjugado revela-se complexo, repleto de nuances que acabem exigindo instrumentais teóricos e metodológicos no intuito de uma construção disciplinada de conhecimentos sociológicos acerca de uma temática tão diversa. Diante de tal imperativo é possível identificar algumas significativas contribuições da obra da socióloga francesa Monique de Saint-Martin.

Monique Saint-Martin é diretora de estudos na Escola de Estudos Avançados em Ciências Sociais (EHESS) e sua obra (Idem, 2008) (SAINT-MARTIN, 1993) (Idem, 1995) (Ibidem 2008) (Ibidem et al, 2008) versa sobre grupos dominantes (em especial na França), movimentos sociais, os processos de ensino e a "história das relações políticas e acadêmicas entre a URSS / Rússia, os países da Europa Central [...] e do Magrebe" (região ocidental do norte do continente africano Marrocos, Tunísia, Argélia, Mauritânia, Saara Ocidental). ${ }^{4}$

\footnotetext{
${ }^{2}$ Genericamente, o termo capital será aqui compreendi enquanto "[...] riqueza que gera mais riqueza, capaz de se reproduzir”. Disponível em http://piaui.folha.uol.com.br/materia/piketty-e-nos/; acesso em 27/01/2017.

3 "Para sociologia, mobilidade social é um conceito de extrema importância uma vez que tal atributo representa o nível de deslocamento social dentro dos vários estratos que existem na sociedade". Disponível em http://cafecomsociologia.com/2013/01/conceito-e-tipos-de-mobilidade-socia.html; acesso em 19/01/2017.
}

\footnotetext{
${ }^{4}$ Disponível em http://iris.ehess.fr/index.php?740; acesso em 02/01/2017.
} 


\section{Fronteiras, classes sociais e trajetórias}

Nos trabalhos de Saint-Martin, o conceito de fronteira pode ser compreendido enquanto uma demarcação que, econômica, cultural e espacialmente, separa os agentes sociais reconhecidamente diferentes entre si no convívio social. Tais separações ${ }^{5}$ apresentam uma ampla diversidade, pois delimitam os perímetros das classificações sociais, evidenciam as desigualdades acerca dos agentes sociais na vida social e também possibilitam situações de troca e comunicação. Diante de tal dinâmica, é possível observar nas fronteiras sociais, processos de construção, estabilização e transgressão, que estão sistematicamente interligados conforme as situações e orientações dos agentes sociais, bem como as suas "experiências educativas e acontecimentos desencadeadores pouco 'previsíveis' e aos As fronteiras sociais desempenham, às vezes, o papel de uma "muralha" que protege de riscos, e, noutras vezes, representam um "fosso" a ser transposto em busca de escapatória. Cada fronteira atravessada marca as histórias familiais em um sentido positivo (de promoção) para uns e, negativo (de desclassificação) para outros. Assim,

As fronteiras representam as linhas que os membros de cada família experimentaram, em conjunto ou individualmente, em sua travessia no espaço social. Nesse jogo de deslocamentos, desejados ou sofridos, que se intensificou nos últimos anos, estabelece-se

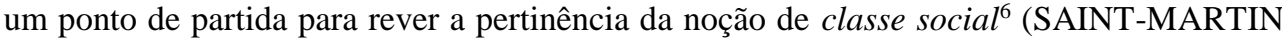
et al, 2008, p. 136).

É verossímil sustentar que o "processo definidor de fronteiras sociais é o desfecho das lutas e conflitos pela classificação social (classement) e contra a desclassificação (déclassement)" (BOURDIEU, 1979, apud, LABACHE; SAINT-MARTIN, 2008, p. 335). Ao abordarmos processualmente esse fenômeno, destacando a dimensão simbólica dos processos de construção, percepção e pertencimento das fronteiras, podemos “observar as antigas desigualdades 'em ação', e as novas desigualdades 'em construção"” (SAINT-MARTIN et al, 2008, p. 136).

O conceito de classe social permeia as fronteiras sociais, no entanto,

\footnotetext{
5 “As fronteiras separam o 'nós' do 'eles' e interrompem, circunscrevem ou produzem segregações na distribuição de populações ou de atividades dentro das sociedades. Essas fronteiras não são dadas, constroem-se, ultrapassam-se e desconstroem-se no tempo e com o tempo" (LABACHE; SAINT-MARTIN, 2008, p. 335).

6 “[...] o primeiro sentido do conceito de classe é puramente teórico, ou seja, é um recurso intelectual que ordena e distribui os indivíduos em categorias mais ou menos fixas. O segundo sentido é descritivo, já que pretende representar de maneira sistemática e abrangente a estrutura social. E o terceiro é interpretativo, uma vez que permite não só ler e exprimir a realidade social, mas entender sua dinâmica - isto é, o comportamento dos agentes sociais". Disponível em http://adrianocodato.blogspot.com.br/2009/05/uma-introducao-ao-conceito-de-classe.html; acesso em 24/01/2017.
} 
[...] as classes sociais não são consideradas conjuntos homogêneos baseados em posições econômicas estritas e em franca oposição, e tampouco como totalidades socioculturais sem fraturas e circunscritas às fronteiras nacionais. Efetivamente, as classes não são formadas em espaços fechados (Idem, p. 138).

Nesta flexibilidade, a reflexão referente às relações das classes sociais torna-se uma possibilidade metodológica real. Assim, fica viável descrever "as trajetórias de mobilidade (ascendente ou descendente) ou de estagnação social, identificando modelos familiais de ascensão social pela via escolar e outros por aliança matrimonial", bem como observar "percursos menos ascendentes, e mesmo de desqualificação, geralmente ligados à migração.” (Ibidem, p. 140). Diante dessa logística, é exequível perceber as fronteiras geográficas, profissionais, econômicas, étnicas e educacionais que balizam os diversos campos sociais e vigoram diante dos agentes sociais presentes, em especial, aqueles sistematizados em grupos familiares.

\title{
Famílias, capitais, rupturas e reconversões
}

São questões destacadas pela autora: as marchas de construção, estabilização e transgressão de fronteiras, juntamente com toda a dinâmica (de comunicação e de manutenção ou ruptura) das trajetórias de indivíduos e/ou famílias pertencentes a classes sociais. Pois:

\begin{abstract}
Sem pretender identificar esquemas de percepção "próprios" a cada classe, trata-se de explicitar alguns elementos distintivos nas maneiras como as famílias das diferentes classes sociais percebem as fronteiras que as separam e/ou as aproximam das outras classes, bem como analisar até que ponto elas tendem a se definir por seu grupo de pertencimento, assim como pelas relações estabelecidas com os outros grupos sociais identificados. Essas identificações e oposições contribuem para dar sentido à vida de cada pessoa: de um lado, elas servem para interpretar a vida de cada um - tornando-a compreensível - e, de outro, participam da mobilização de recursos pessoais e familiais, em vista de uma reprodução ou transformação da situação vivida. Essa mobilização é particularmente evidente entre as gerações, e constitui um elemento decisivo da experiência social e educacional que os pais buscam dominar e a partir da qual eles orientam a vida de seus filhos (SAINT-MARTIN $e t$ $a l, 2008$, p. 142).
\end{abstract}

Por meio de tal abordagem, as trocas intergeracionais emergem enquanto realidades relevantes e chamam atenção para a importância das relações familiares ${ }^{7}$ numa definição flexível

\footnotetext{
7 "Para compreender como a família passa de uma ficção nominal a grupo real, cujos membros estão unidos por intensos laços afetivos, e preciso levar em conta todo o trabalho simbólico e prático que tende a transformar a obrigação de amar em disposição amorosa e a dotar cada um dos membros da família de um "espirito de família" gerador de devotamentos, de generosidades, de solidariedades (ele se expressa tanto nas inúmeras trocas comuns e continuadas da vida cotidiana, trocas de dádivas, de serviços, de ajuda, de visitas, de atenções, de gentilezas etc., quanto nas trocas extraordinárias e solenes das festas familiares - frequentemente sancionadas e eternizadas por fotografias que consagram a integração da família reunida)” (BOURDIEU, 1996, p. 129-130).
} 
de classe social. Nessa compreensão, o sentimento de pertencer a uma classe social é uma situação em que fronteiras, objetivas e subjetivas, externas e internas, são demarcadas, sendo que tal contorno está intimamente ligado às trajetórias e às experiências de conservação e/ou ruptura por parte das famílias envolvidas.

O fenômeno das trocas intergeracionais remete à questão da herança (ALMEIDA et al, 2015). Assim, os capitais repassados de "pai para filho" (em circunstâncias que revelam trajetórias fiadas por desejos de consolidação ou interrupção) oportunizam o que a autora define como iniciativas de reconversões; as quais, para além da posse de recursos, estão diretamente ligadas às posições das famílias no espaço social (SAINT-MARTIN, 1995).

Ao estudar a aristocracia francesa, Saint-Martin ressalta que a

[...] observação e o estudo aprofundado das estratégias de reconversão dos membros das diferentes fracções das classes dirigentes, dos seus êxitos e fracassos, da tendência para o conservadorismo ou para a inovação constituem um interessante ponto de partida na análise das transformações e das reestruturações das elites e dos poderes. Com as reconversões, encontramo-nos, com efeito, não só no centro do processo de ruptura das carreiras ou dos itinerários mais clássicos, mas também no centro do processo de desvalorização ou de reavaliação dos diversos recursos económicos, culturais, sociais e simbólicos detidos pelos diferentes agentes (Idem, p. 1023).

Conforme a autora, quando se acrescenta à discussão a temática das relações de poder, perante contextos de estabilização e/ou ruptura emergem estratégias de reconversões que

[...] dependem, em larga medida, do estado do sistema dos instrumentos de reprodução (estado das leis de direito sucessório, do mercado de trabalho, do sistema escolar, etc.) e do estado (volume e estrutura) dos recursos (capitais - grifos nossos) económicos, culturais, sociais e simbólicos que os diversos grupos procuram reproduzir; elas dependem ainda da avaliação que é feita das oportunidades de manutenção na posição ocupada e envolvem em elevado grau as disposições e perspectivas em relação ao futuro (Ibidem, p. 1024).

Os distintos capitais "são moeda de troca nas lutas entre os diversos grupos". Nesse raciocínio vigoram processos de valorização e/ou de desvalorização acerca dos recursos disponíveis. Assim, “enquanto uma certa espécie de capital, por exemplo, um título escolar, corre sempre o risco de se desvalorizar ou perder legitimidade, outra pode rapidamente valorizar-se" ${ }^{\text {. }}$. Por

8 “[...] é o caso do capital económico ou financeiro na maioria das sociedades contemporâneas" (SAINT-MARTIN, 1995, p. 1024). 
tal circunstância, as estratégias de reconversão fundamentam-se na "acumulação de diferentes espécies de capital" com o intuito de garantir proteção "contra a desclassificação ou o declínio social" (Ibidem). Juntamente com o atributo de geração de riqueza, os capitais adquiridos pelos agentes ao longo de suas respectivas vivências podem ser compreendidos enquanto recursos mobilizadores que proporcionam hierarquia à estrutura social (MATOS, 2009); autênticos combustíveis de mobilidade social.

Interesses e distribuição desigual de capitais fundamentam conjunções que resultam em conflitos Nos processos históricos são contextualmente avaliados e reavaliados conforme as trajetórias em questão. Nessa lógica, ao analisar os grupos dirigentes na França, a autora conclui que:

[...] A predisposição para as deslocações no espaço social, para as reconversões das posições e das disposições, torna-se incompreensível se não forem tidas também em conta as alianças matrimoniais ou profissionais, as solidariedades, as redes de pertença, bem como os comportamentos económicos, as práticas sucessórias e educativas (SAINTMARTIN, 1995, p. 1037).

A referida conclusão proporciona uma reflexão sobre a significativa importância dos grupos familiais na manutenção e reprodução do exercício do poder. Uma vez que, os diversos tipos de capitais (econômicos, sociais, simbólicos) disponíveis aos grupos dirigentes são herdados e desigualmente estabelecidos em decursos de longa duração. Nessa proposição, [...] "uma origem social elevada, a antiguidade do pertencimento à burguesia e a passagem por uma grande école (escola) facilitam amplamente o acesso aos grupos dirigentes" (SAINT-MARTIN, 2008, p. 50). Desse modo, Saint Martin ressalta a importância da escola na formação e no estabelecimento das elites administrativas, econômicas e políticas na história social da França:

Estudar os sistemas de ensino secundário e superior e as relações das escolas ou universidades com o Estado surge como ponto de partida indispensável a um estudo sociológico das elites. A socialização e a formação dos membros das futuras elites dependem estreitamente das instituições educativas (escolas de elite, privadas ou públicas, grandes liceus, grandes écoles, etc.) que favorecem a estruturação dos grupos, a constituição de redes e a aprendizagem de modos de gestão das relações e do exercício da autoridade (Idem, p. 52).

Conforme a autora, diante de tal conjectura, 
[...] as famílias mais ricas se caracterizam por uma «obsessão pela transmissão»; eles gerem com vigilância a educação, as alianças matrimoniais dos filhos, os espaços de residência e de encontro, as relações. Para as grandes famílias da aristocracia e da grande burguesia, a duração no tempo é fundamental (Ibidem, p. $57)$.

As escolas em sintonia com as famílias. De acordo com Saint-Martin, e para irmos além do senso comum, essa harmonia só é compreendida enquanto tal, à medida que os agentes sociais envolvidos as concebam como estruturas objetivas que contemplam suas diversas estratégias de conservação de posições nos complexos contextos de vivência social.

\section{Considerações finais}

A sistematização dos conceitos de fronteira, trajetória, ruptura e reconversão é um artifício que pode ser pensado considerando que uma sociedade humana é constituída por campos sociais; os quais são definidos como espaços teóricos conjuntos, microcosmos relativamente autônomos que dispõem de lógicas próprias e emergem das diferenciações sociais. Um campo é tanto um "campo de forças", uma composição que compele os indivíduos, instituições e grupos (agentes sociais) nele enredados, quanto um "campo de lutas", em que os agentes sociais obram conforme suas posições junto às relações de forças. Nessa dinâmica, os agentes operam no sentido de conservar ou transformar a estrutura do campo social a que cada um corresponde (BOURDIEU, 1996).

O agente social (indivíduo, instituição ou grupo) é semiautônomo (ativo e passivo), incorpora as relações com a estrutura social e reproduz as mesmas por meio dos habitus; esses definidos enquanto produtos coletivos que orientam as ações dos agentes; instrumentos capazes de auxiliar na reflexão acerca da relação (e da mediação) entre as sujeições sociais exteriores e a subjetividade dos agentes sociais (THIRY-CHERQUES, 2006). É pelos habitus que os agentes interiorizam valores, normas e princípios sociais que asseguram a adequação entre suas ações e a realidade social objetiva (BOURDIEU, 1996). A referida definição de habitus está entrecruzada aos conceitos de fronteira, trajetória, ruptura e reconversão.

Diante deste cenário, juntamente com "o recrutamento e a seleção das elites, as suas trajetórias e carreiras", a edificação de suas respectivas identidades e "os processos de composição e 
recomposição" devem ser ponderados. Nesse ponto, “o estudo da repartição desigual dos poderes e dos centros de decisão", que averigua "o acréscimo do poder de uns [...] relativamente à redução do poder de outros". Conforme Saint Martin, "a análise sociológica deverá ter por objeto os desacordos e as lutas decorrentes dessa desigual distribuição de poderes a par das próprias reestruturações" (SAINT-MARTIN, 1995, p. 1023).

O dueto dominação / mobilidade social "resulta não apenas da herança de patrimônio, mas também de um sem-número de outras coisas (tempo livre, rede de relações sociais, hábitos culturais, mais chance de errar e recomeçar etc.)". Tais elementos possibilitam oportunidades de ascensão social e apresentam, "de alguma maneira, têm relação com a riqueza das gerações passadas" ". Assim, as fronteiras, as trajetórias, as rupturas e as reconversões cerram uma relação sistemática alicerçada por estruturas familiares. Portanto, emerge uma interessante ocasião favorável para ressaltar a relevância da família nas análises políticas e sociais.

\section{Referências}

ALMEIDA, A. M. F.; PEROSA, G. S.; ERNICA, M. (2015). "Contribuição para uma história de 'Os herdeiros' - Entrevista com Monique de Saint-Martin”. Educação e Sociedade, jan/mar, vol. $36, \mathrm{n}^{\circ} 130$, p. 181-194.

BOURDIEU, P. (1996). Razões práticas: sobre a teoria da ação. Campinas: Papirus.

LABACHE, L.; SAINT-MARTIN, M. (2008). "Fronteiras, trajetórias e experiências de ruptura". Educação e Sociedade, mai/ago, vol. 29, nº 103, p. 333-354.

MARQUES, E. C. (1999). "Redes sociais e instituições na construção do Estado e da sua permeabilidade". Revista Brasileira de Ciências Sociais, out., vol. 14, n 41, p. 45-67.

MATOS, H. (2009). Capital social e comunicação: interfaces e articulações. São Paulo: Summus.

SAINT MARTIN, M. (1993). L'espace de la noblesse. Paris: Métailié.

. (1995). "Reconversões e reestruturações das elites: o caso da aristocracia francesa”. Análise Social, vol xxx, nº 134, p. 1023-1039.

\footnotetext{
${ }^{9}$ Disponível em http://piaui.folha.uol.com.br/materia/piketty-e-nos/; acesso em 27/01/2017.
} 
. (2008). "Da reprodução às recomposições das elites: as elites administrativas, econômicas e políticas na França”. TOMO, jul/dez, n 13, p. 43-73.

; ROCHA, D.C.; HEREDIA, M. (2008). "Trocas intergeracionais e fronteiras sociais na França”. Tempo Social, jun, vol 20, n 1, p. 135-162.

THIRY-CHERQUES, H. R. (2006). "Pierre Bourdieu: a teoria na prática". Rev. Adm. Pública, vol.40, n.1, pp.27-53.

VASCONCELOS, P. (2015). “'Grandes famílias', política e estratégias escolares: conversões, reconversões e legitimação". Contraponto, jan/jul, v. 2, n. 1, p. 228-248.

\section{Documentos de acesso exclusivo em meio eletrônico}

"Conceito e tipos de mobilidade social" - Disponível em http://cafecomsociologia.com/2013/01/conceito-e-tipos-de-mobilidade-socia.html; $\quad$ acesso em 19/01/2017.

"Membres / Membres statutaires / Monique de SAINT-MARTIN" - Disponível em http://iris.ehess.fr/index.php?740; acesso em 02/01/2017.

"Piketty e nós" - Disponível em http://piaui.folha.uol.com.br/materia/piketty-e-nos/; acesso em 27/01/2017.

"Sociologia Política: uma introdução ao conceito de "classe social"”. - Disponível em http://adrianocodato.blogspot.com.br/2009/05/uma-introducao-ao-conceito-de-classe.html; acesso em 24/01/2017. 